\title{
Revisiting the anatomy of the cephalic vein, its origin, course and possible clinical correlations in relation to the anatomical snuffbox among Jordanian
}

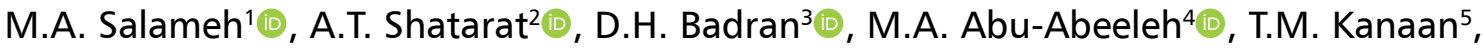 \\ A.M. Bani-Hani ${ }^{4}$, M.Q. Hamdan ${ }^{5}$
}

'Department of Basic Medical Science, Faculty of Medicine, Al Balqa Applied University, Al Salt, Jordan

${ }^{2}$ Department of Anatomy and Histology, Faculty of Medicine, University of Jordan, Amman, Jordan

${ }^{3}$ Dean of the Faculty of Medicine, Hashemite University, Zarqa, Jordan

${ }^{4}$ Department of General Surgery, Faculty of Medicine, University of Jordan, Amman, Jordan

${ }^{5}$ Department of Special Surgery, Faculty of Medicine, University of Jordan, Amman, Jordan

[Received: 11 January 2020; Accepted: 27 March 2020]

Background: The cephalic vein is one of the most distinguished superficial veins of the upper limb. Its clinical value lies in venous access. There is little known about the variation of its formation in relation to the anatomical snuffbox. Hence, anatomical variants in the origin of the cephalic vein are important in clinical practice. Subsequently, this study was designed to examine the variation of the cephalic vein formation in relation to the anatomical snuffbox.

Materials and methods: A cross-sectional study of 438 subjects (722 hands), was prepared to study the cephalic vein among Jordanian students and staff of one of the major governmental Medical College in Jordan, by using infrared illumination system. The obtained data was analysed according to; gender, sidedness, and handedness.

Results: Four sites for the formation of the cephalic vein in relation to the anatomical snuffbox were found. There was a significant relation between gender and sidedness, and the sites of formation of the cephalic vein $(p<0.0001$ and $p=0.048$, respectively).

Conclusions: For the first time this study identified different sites for the formation of the cephalic vein in relation to the anatomical snuffbox. However, regardless of its sites of formation, the cephalic vein was running in $98 \%$ of the examined hands in the anatomical snuffbox. (Folia Morphol 2021; 80, 2: 344-351)

Key words: anatomic variation, cannulation, hand, veins, venous access

\section{INTRODUCTION}

The cephalic vein (CV) as a term originates from the Arabic word al-kefal, which means "outer" and was first used by Muslim physician Ibn Sina, when the term was translated to Latin, cephalic inaccurately was selected to replace the Arabic origin of the term [3]. The $C V$ is a superficial vein that originates from the radial aspect of the dorsal venous network of the

Address for correspondence: Dr. S.T. Amjad, Department of Anatomy and Histology, Faculty of Medicine, University of Jordan, Amman, 11942, Jordan, tel: 009626 5355000, ext. 23434, e-mail: a.shatarat@ju.edu.jo

This article is available in open access under Creative Common Attribution-Non-Commercial-No Derivatives 4.0 International (CC BY-NC-ND 4.0) license, allowing to download articles and share them with others as long as they credit the authors and the publisher, but without permission to change them in any way or use them commercially. 
hand. It is formed when the dorsal digital vein from the radial side of the index finger and the two dorsal digital veins of the thumb join each other. It arises on the roof of the anatomical snuffbox (AS) then crosses the radial styloid process and courses upward on the anterolateral side over the forearm. Then it passes upwards over the antecubital region, where it may receives blood from the median cubital vein, and continues to ascend on the anterolateral side of arm lateral to the biceps muscle in the deltopectoral groove. Later on, the vein passes through the axilla, by piercing the clavipectoral fascia to drain and end into the axillary vein. Throughout its course, the CV has three clinical important regions; it's origin on the hand in the AS, in the cubital fossa and its termination in the axillary vein. The latter two regions were studied and it has been concluded that the $\mathrm{CV}$ has different anatomical patterns in those regions $[6,8$, $13,22]$. However, the anatomical patterns of the CV in the AS seemed to be overlooked.

The AS is a descriptive anatomical term for the triangular hollow on the radial part of the dorsum of the hand, which is formed by depressing skin of muscle contraction; the base is directed to the wrist while the apex is directed to the thumb. The impression is most apparent when the thumb is abducted and extended. It is limited on the ulnar (posterior) side by the extensor pollicis longus (EPL) tendon, whereas on the radial (anterior) side by tendons of the abductor pollicis longus (APL) and extensor pollicis brevis (EPB). The base is formed by the distal margin of the extensor retinaculum, while the apex is created by the attachment of EPL and EPB tendons [5]. The terminal part of the superficial branch of the radial nerve (SBRN) and the CV pass through the superficial fascia that forms in addition to the skin the roof of the AS. The floor is formed by the base of the first metacarpal bone, trapezium, scaphoid and the distal radius [5]. The radial artery (RA) and the extensor carpi radialis tendons are at the bottom of AS [2].

The relation between the CV and the AS has always been underestimated regardless of its clinical value. For example, clinical procedures such as venous cannulation of the $\mathrm{CV}$ in the $\mathrm{AS}$ is a well known site [12]. Placing an arteriovenous fistula which is applied surgically to obtain vascular access between the RA and CV in patients on haemodialysis is another procedure used in this area $[10,19,25]$. Also, it has been shown that, maintaining satisfactory venous drainage of the hand using neurovascular pedicles, which include the transferred digit or the reimplanted digit gives the CV another clinical importance $[9,14$, 21]. The large diameter of the distal part of the $C V$ has been suggested for vein puncture, especially; because this part is easier to view and palpate [9]. Furthermore, it was reported that the vein puncture of CV adjacent to the AS is the ideal site beside the cubital fossa [9]. However, other studies have challenged the access of the $\mathrm{CV}$ in the AS and the distal part of the forearm, for example, Robson et al. [15] and Samarakoon et al. [18] stated that cannulation of the $\mathrm{CV}$ in the distal third of the forearm should be avoided; to prevent any possible injury of the SBRN. Besides, Vialle et al. [24] recommended that CV puncture must be at least $12 \mathrm{~cm}$ above the styloid process of the radius to avoid injury to SBRN.

This valuable relationship between the $C V$ and $A S$ has been mentioned in some studies as findings but not as a full study about these two valuable anatomical structures. For example, it has been reported that sometimes the origin of the $\mathrm{CV}$ from the dorsal venous network of the hand can be recognized in the roof of the AS. Another study has demonstrated that the SBRN was largely related to the $\mathrm{CV}$ in $80 \%$ of the studied forearms, which underlay the CV [14]. Furthermore, within the AS there were connections between the vena comitantes of the RA and the $C V$, and the $C V$ was found considerably in the ulnar part of the AS [16, 20]. A case study for dissecting upper limbs of 2 months infant showed normal beginning of CV in the roof of the AS, no variation in the vein of the right upper limb, while the left upper limb showed abnormal running up and continuation of CV [15]. A cadaveric study of 10 cadavers was carried out to demonstrate the variations in the tendons of the AS in a Malaysian, it was found that 2 hands of different specimens showed the $\mathrm{CV}$ in the AS [23]. Therefore, the present study aimed to study and describe in details the origin of the CV in relation to AS. Also, to characterize any possible anatomical patterns for $\mathrm{CV}$ in the AS.

\section{MATERIALS AND METHODS}

\section{Subjects}

A total number of 438 subjects were included in the study; 217 males and 221 females. A total number of 722 hands were examined. They were chosen randomly from the Hashemite University. The age group considered was from 18-35 years. A total of 239 hands with injuries, scars, burns and hairy skin, were excluded (exclusion rate $33 \%$ ). In females; 39 right hands 
and 49 left hands were excluded, while in males; 69 right hands and 84 left hands were excluded.

Subjects were informed in detail about the procedure and written consent was signed. The study was approved by the Institution Review Board of the Hashemite University (IRB\#) P.0/222/1704841.

\section{Instruments}

The infrared (IR) vein illumination system (Sure vein ZD-JM-260-01) has been used to identify the formation of the CV. It utilises 750-980 nm wavelength of infrared light, with an effective distance of projection by $29-31 \mathrm{~cm}$.

\section{Study design}

The procedure was conducted in a dark room with a temperature between $24-26^{\circ} \mathrm{C}$. Subjects instructed to sit and rest their fisted hand in midprone position on the enhancer. Before exposing the hand to the IR beam, the targeted area was carefully identified. The targeted area was the AS includes the medial and lateral boundaries. It is limited on the medial side by EPL tendon, whereas on the lateral side by tendons of APL and EPB, the styloid process of the radial bone which was taken as the proximal boundary and the tendons of the AS they approximate to form the apex. The apex, which directed into the first metacarpophalangeal joint considered the distal boundary of the targeted area.

The EPL and APL tendons were identified and were marked by putting a dot by a pen on both of them. The targeted area of the examined hand was then exposed to the IR beam. The CV was followed in the AS and at the proximal forearm on the lateral side to be assured that it was the CV.

The targeted area of the examined hand was then exposed to the IR beam. Each subject had two photos for the right and left hands; the CV was photographed by a mobile phone camera. Images were carefully analysed and grouped according to the formation of the CV in relation to the AS.

\section{Statistical analysis}

Data analysis was performed using IBM SPSS Statistics version 22 software. Chi-square test was used to test the association between gender, sidedness and handedness, and the sites of formation of the CV. Statistical comparisons were made by Student's unpaired t-test. The association was considered statistically significant if $p<0.05$.
Table 1. Demographic and experimental characteristics of the final population of the formation of the cephalic vein in relation to anatomical snuffbox

\begin{tabular}{lccc}
\hline Characteristic & $\begin{array}{c}\text { Number } \\
\text { of subjects }\end{array}$ & $\begin{array}{c}\text { Total number } \\
\text { of hands in } \\
\text { the study }\end{array}$ & $\begin{array}{c}\text { Hands excluded } \\
\text { from the study }\end{array}$ \\
\hline $\begin{array}{l}\text { Gender: } \\
\text { Male }\end{array}$ & $217(49 \%)$ & $368(51 \%)$ & $151(63 \%)$ \\
Female & $221(51 \%)$ & $354(49 \%)$ & $88(37 \%)$ \\
Hand: & & & \\
Right & & $368(51 \%)$ & $108(45 \%)$ \\
Left & $354(49 \%)$ & $131(55 \%)$ \\
Symmetry: & & & \\
Yes & $196(45 \%)$ & \\
No & $242(55 \%)$ & \\
\hline
\end{tabular}

\section{RESULTS}

The final population of the study consisted of 438 subjects; 217 males and 221 females (Table 1). The total number of the hands was 722 hands. The number of the hands included in this study was 368 in males and 354 in females (Table 1). The number of right hands included in this study was 368 and the number of left hands was 354. Two hundred and eighty three hands were excluded (exclusion rate of $33 \%$ ).

It was found during the examination of the CV, the formation of the CV was variable in relation to the AS (Fig. 1). Thus, the CV was formed either inside the AS (type A) or outside it (type B), type A was found in $305(63 \%)$ of the examined hands and type $B$ was found in 178 (37\%) of the examined hands. Further examination showed that the CV was not only formed in the AS (type A) but also was formed at different levels (Table 2). Type A1 was present in $87(18 \%)$ of the examined hands, where the CV was formed in the distal part of the AS (Fig. 2). Type A2 was the most common being in 218 (45\%) of the examined hands (the CV was formed in the proximal part of the AS (Fig. 3).

Also, there were two types of Bs (according to their location medial or lateral to the AS): type B1 ( $n=170,35 \%$ ) of the examined hands, where the CV was formed medially to the EPL tendon (Fig. 4), and type B2 ( $n=8,2 \%$ ) of the examined hands, which was the least common, (the CV was formed lateral to the APL tendon) (Fig. 5). 


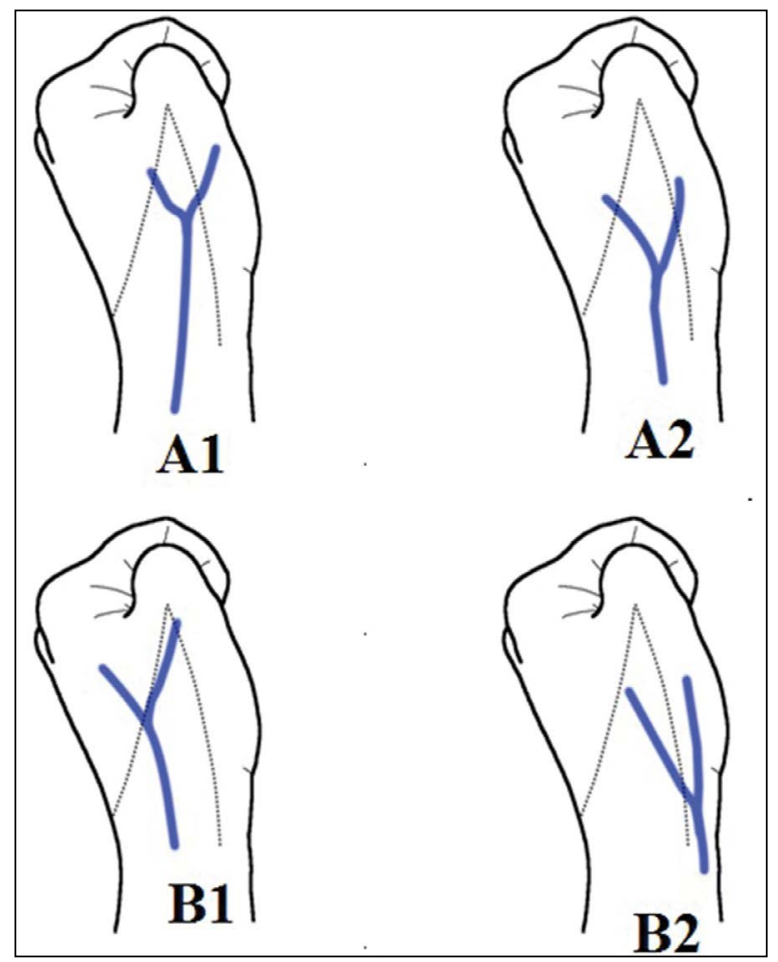

Figure 1. Illustration shows the different sites of formation of the cephalic vein in relation to the anatomical snuffbox.

Table 2. Subtotal frequencies of the anatomic variants under study of the formation of cephalic vein (CV) in relation to the anatomical snuffbox (AS) ( $n=483$ )

\begin{tabular}{lc}
\hline The formation of the CV in relation to the AS & Subtotal (\% total) \\
\hline Inside the AS: & $305(63 \%)$ \\
Distally & $87(18 \%)$ \\
Proximally & $218(45 \%)$ \\
Outside the AS: & $178(37 \%)$ \\
Medially & $170(35 \%)$ \\
Laterally & $8(2 \%)$ \\
\hline
\end{tabular}

The most common site of formation of the CV was in the AS proximally in both males 98 (48\%) and females 120 (43\%), but not in both hands, where the formation of the CV in AS proximally was proportionally greater in right hands 120 (46\%) compared with left hands 98 (44\%) (Table 3). While the formation of the CV outside the AS medially was greater in left hands 100 (45\%) (Table 3). In males, the most common site of formation of the CV was in the AS proximally in right and left hands 55 (50\%) and 43 (46\%), respectively, while in females, the most common site of formation of the CV was different in both hands; was in the AS

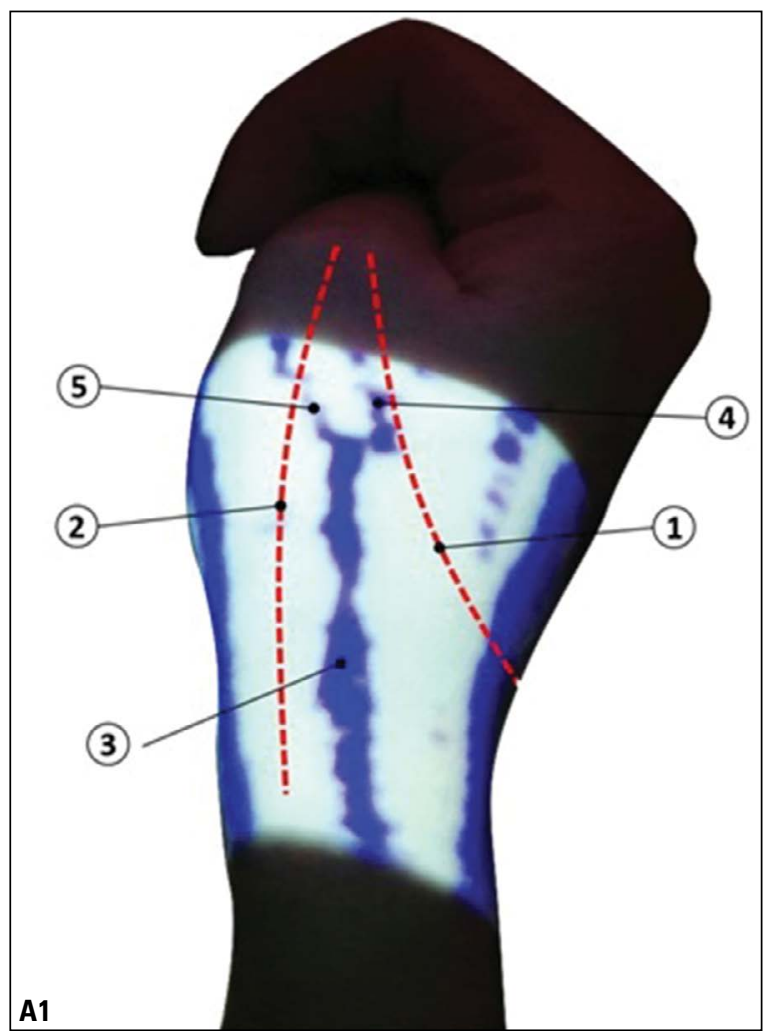

Figure 2. Right hand shows the presumed position of the tendon of extensor pollicis longus muscle (1), the presumed position of the tendons of abductor pollicis longus and extensor pollicis brevis muscles (2), the cephalic vein as it begins in the distal part of the anatomical snuffbox (3), continuation of the medial digital vein of the thumb (4) and continuation of the lateral digital vein of the thumb (5) where they resemble the origin of the cephalic vein.

proximally in right hands 65 (43\%), but was outside the AS medially in left hands 64 (49\%) (Table 4). Also, the formation of the CV in AS proximally was proportionally greater in left handed 98 (44\%) compared with right handed 83 (41\%) (Table 3). Moreover, it was noted that the symmetry of the site of formation of the CV between both hands in the same subject (in the total sample) was 107 (25\%), the symmetry in females was 64 (15\%), which is greater than the symmetry in males $43(10 \%)$ (Table 5$)$.

Statistical analysis using the chi-square test, there was a significant relation between both right and left hands, and site of the CV formation ( $p=0.048$ ). There was a significant relation between both females and males, and the site of the CV formation ( $p<0.0001)$. Also, there was significant relation between sidedness and site of CV formation in males ( $p=0.01)$, and in females $(p=0.009)$. There was not a significant relation between right handed and left handed subjects and the site of the CV formation $(p=0.081)$. 


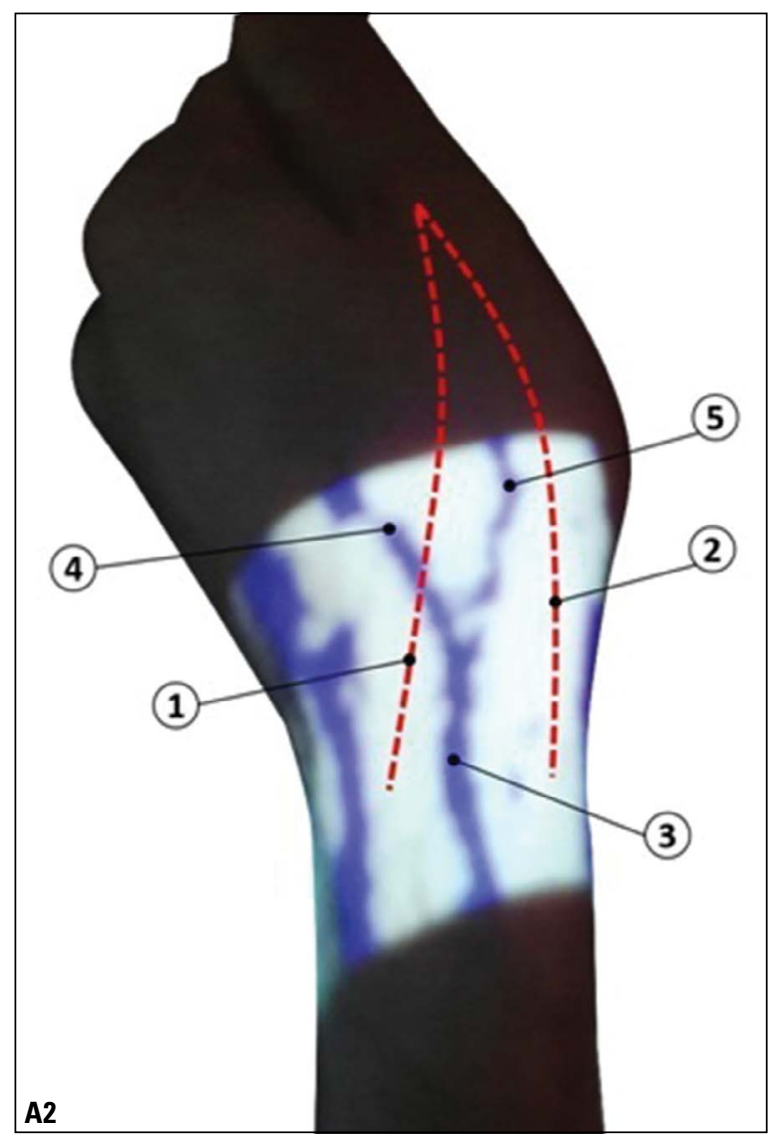

Figure 3. Left hand shows the presumed position of the tendon of extensor pollicis longus muscle (1), the presumed position of the tendons of abductor pollicis longus and extensor pollicis brevis muscles (2), and the cephalic vein (3) as it begins in the proximal part of the anatomical snuffbox, (4) continuation of the medial digital vein of the thumb (4) and continuation of the lateral digital vein of the index (5) where they resemble the origin of the cephalic vein.

\section{DISCUSSION}

The main finding of the present study was the characterisation of the course of the $\mathrm{CV}$ in relation to the AS. Two main origins have been demonstrated; the first one was identified within the AS either in its proximal or in its distal parts. The second origin, however, was identified outside the AS either in its medial or lateral sides. However, despite these different origins of the CV, it was running in the AS in $98 \%$ of the examined hands.

The IR illuminator has been used before in recognition of different veins in different areas, like the veins on the cubital fossa and the veins on the dorsum of the hand $[4,7,17]$. It should be noted that the present study did not examine the course of veins that formed the CV as it was not one of the aims of this study and because these veins cannot be imaged at

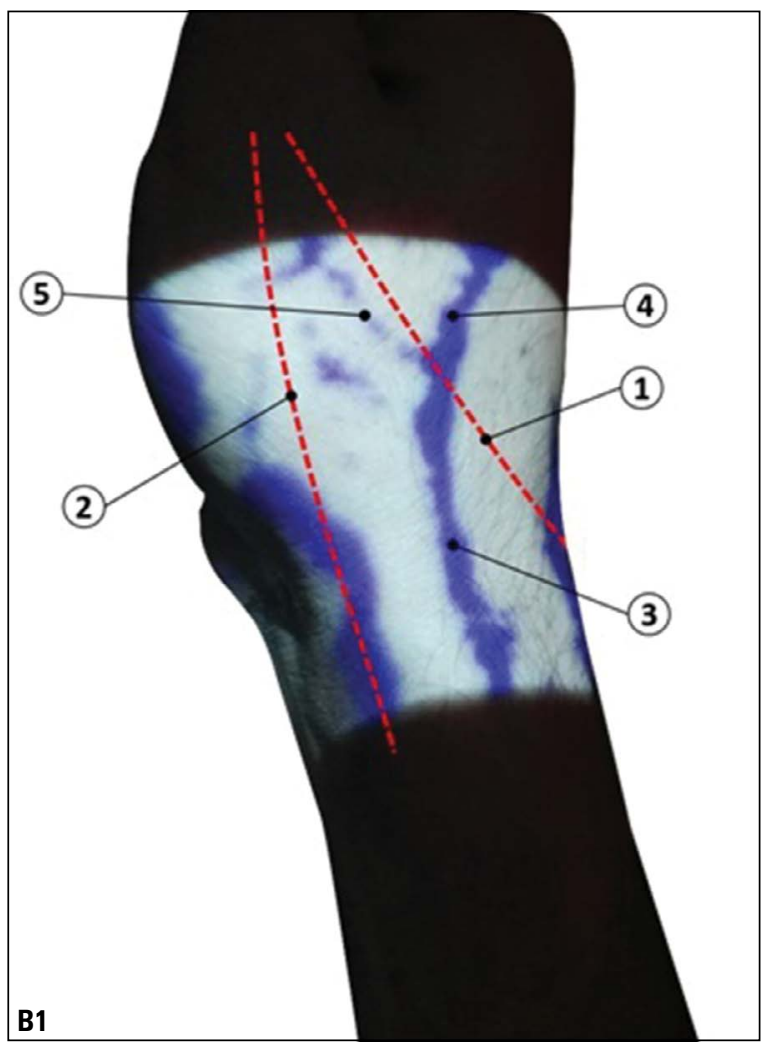

Figure 4. Right hand shows the presumed position of the tendon of extensor pollicis longus muscle (1), the presumed position of the tendons of abductor pollicis longus and extensor pollicis brevis muscles (2), and the cephalic vein (3) which begins outside the anatomical snuffbox, medial to the extensor pollicis longus tendon, continuation of the medial digital vein of the thumb (4) and continuation of the lateral digital vein of the index (5) where they resemble the origin of the cephalic vein.

the same time with CV due to the limited area that can be measured by IR illuminator. However, it has been reported that the origin of the $\mathrm{CV}$ is usually from the dorsal superficial venous network of the hand, specifically from the radial side, also the veins receive both dorsal digital veins from the thumb [24]. It is also worth mentioning that, in each examined hand the course of the CV was traced, separately, on the distal part of the lateral aspect of the forearm to confirm that the examined vein was the CV. The courses of the veins that formed the $\mathrm{CV}$ and its course proximal to the AS could be part of future projects as they need further examinations.

One of the most important findings in the present study is the demonstration of the relation of the CV and the AS. Despite the different sites of formation of the CV, it was running in the AS in $98 \%$ of the examined hands. These results are in agreement with another study in which the presence of the CV in the 


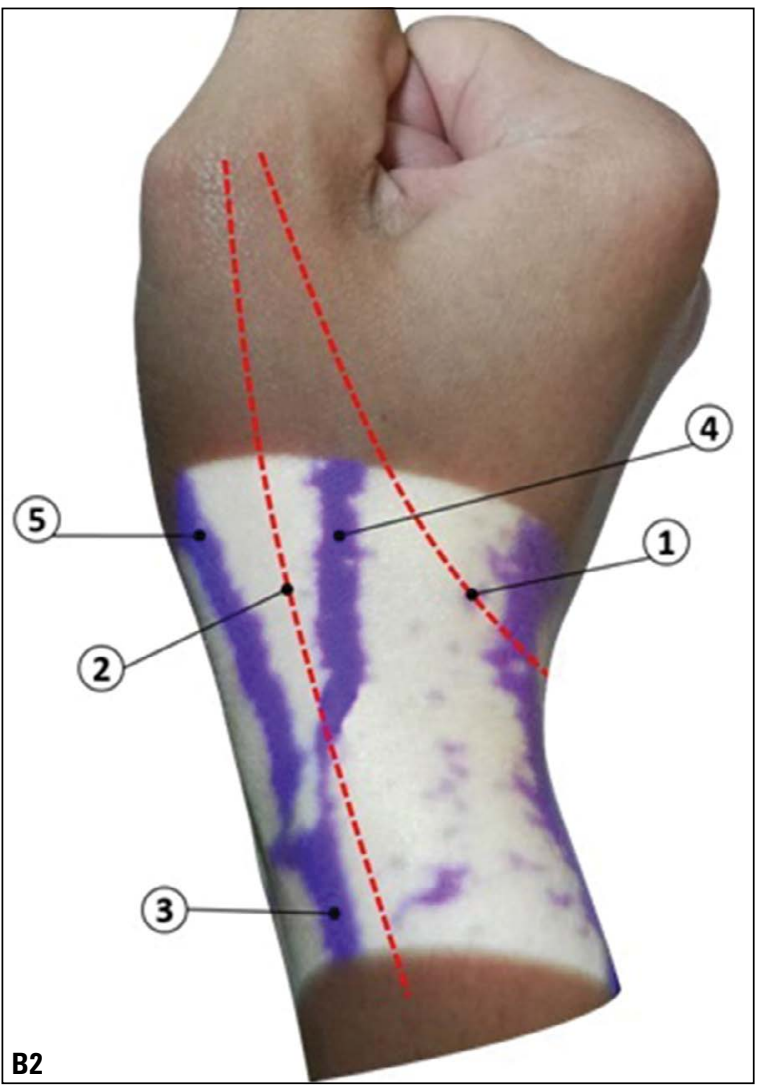

Figure 5. Right hand shows the presumed position of the tendon of extensor pollicis longus muscle (1), the presumed position of the tendons of abductor pollicis longus and extensor pollicis brevis muscles (2), and the cephalic vein (3) which originates outside the anatomical snuffbox, lateral to the abductor pollicis longus tendon, continuation of the medial digital vein of the thumb (4) and continuation of the lateral digital vein of the thumb (5) where they resemble the origin of the cephalic vein.

AS has been identified during arteriovenous fistula procedures in all patients [10]. Another anatomical study that revisited the anatomy of the AS and its contents also found and described the CV and its communications in the AS [20]. The present study did not investigate the reasons behind this very well established a relationship between the $\mathrm{CV}$ and AS. However, we may suggest that based on the anatomical course of the veins that participate in the formation of the $\mathrm{CV}$, that they have no other options but to run through the AS or near to it. The dorsal digital vein from the radial side of the index finger which lies on the lateral side of the hand and the two dorsal digital veins of the thumb coming from the most lateral side of the hand (the thumb) find the nearest point to join each other in the AS to form the CV on the dorsum of the hand. In fact, this should not be surprising as it has been reported that superficial veins of the hand are running in radial and ulnar groups [4]. The radial group drains a much
Table 3. Frequency and number of sites of formation of the cephalic vein (CV) in relation to the anatomical snuffbox (AS), according to gender ( $n=483)$, sidedness $(n=483)$ and handedness (laterality) $(n=228)$

\begin{tabular}{|c|c|c|c|c|c|c|}
\hline $\begin{array}{l}\text { The formation } \\
\text { of the CV in } \\
\text { relation to } \\
\text { the AS }\end{array}$ & Male & Female & $\begin{array}{l}\text { Right } \\
\text { hand }\end{array}$ & $\begin{array}{l}\text { Left } \\
\text { hand }\end{array}$ & $\begin{array}{c}\text { Right } \\
\text { handed }\end{array}$ & $\begin{array}{c}\text { Left } \\
\text { handed }\end{array}$ \\
\hline $\begin{array}{l}\text { Inside the AS } \\
\text { distally }\end{array}$ & $\begin{array}{c}42 \\
(21 \%)\end{array}$ & $\begin{array}{c}45 \\
(16 \%)\end{array}$ & $\begin{array}{c}64 \\
(25 \%)\end{array}$ & $\begin{array}{c}23 \\
(10 \%)\end{array}$ & $\begin{array}{c}55 \\
(27 \%)\end{array}$ & $\begin{array}{c}2 \\
(8 \%)\end{array}$ \\
\hline $\begin{array}{l}\text { Inside the AS } \\
\text { proximally }\end{array}$ & $\begin{array}{c}98 \\
(48 \%)\end{array}$ & $\begin{array}{c}120 \\
(43 \%)\end{array}$ & $\begin{array}{c}120 \\
(46 \%)\end{array}$ & $\begin{array}{c}98 \\
(44 \%)\end{array}$ & $\begin{array}{c}83 \\
(41 \%)\end{array}$ & $\begin{array}{c}12 \\
(44 \%)\end{array}$ \\
\hline $\begin{array}{l}\text { Outside the AS } \\
\text { medially }\end{array}$ & $\begin{array}{c}58 \\
(29 \%)\end{array}$ & $\begin{array}{c}112 \\
(40 \%)\end{array}$ & $\begin{array}{c}70 \\
(27 \%)\end{array}$ & $\begin{array}{c}100 \\
(45 \%)\end{array}$ & $\begin{array}{c}60 \\
(30 \%)\end{array}$ & $\begin{array}{c}13 \\
(48 \%)\end{array}$ \\
\hline $\begin{array}{l}\text { Outside the AS } \\
\text { laterally }\end{array}$ & $\begin{array}{c}5 \\
(3 \%)\end{array}$ & $\begin{array}{c}3 \\
(1 \%)\end{array}$ & $\begin{array}{c}6 \\
(2 \%)\end{array}$ & $\begin{array}{c}2 \\
(1 \%)\end{array}$ & $\begin{array}{c}3 \\
(2 \%)\end{array}$ & $\begin{array}{c}0 \\
(0 \%)\end{array}$ \\
\hline Subtotal & $\begin{array}{c}203 \\
(42 \%)\end{array}$ & $\begin{array}{c}280 \\
(58 \%)\end{array}$ & $\begin{array}{c}260 \\
(54 \%)\end{array}$ & $\begin{array}{c}223 \\
(46 \%)\end{array}$ & $\begin{array}{c}201 \\
(88 \%)\end{array}$ & $\begin{array}{c}27 \\
(12 \%)\end{array}$ \\
\hline
\end{tabular}

Table 4. Right and left hands frequency and number of sites of formation of the cephalic vein (CV) in relation to the anatomical snuffbox (AS) according to gender

\begin{tabular}{|c|c|c|c|c|}
\hline \multirow{2}{*}{$\begin{array}{l}\text { The formation of } \\
\text { the CV in relation } \\
\text { to the AS }\end{array}$} & \multicolumn{2}{|c|}{ Male } & \multicolumn{2}{|c|}{ Female } \\
\hline & $\begin{array}{l}\text { Right } \\
\text { hand }\end{array}$ & $\begin{array}{l}\text { Left } \\
\text { hand }\end{array}$ & $\begin{array}{l}\text { Right } \\
\text { hand }\end{array}$ & $\begin{array}{l}\text { Left } \\
\text { hand }\end{array}$ \\
\hline Inside the AS distally & $30(27 \%)$ & $12(13 \%)$ & $34(23 \%)$ & $11(9 \%)$ \\
\hline $\begin{array}{l}\text { Inside the AS } \\
\text { proximally }\end{array}$ & $55(50 \%)$ & $43(46 \%)$ & $65(43 \%)$ & $55(42 \%)$ \\
\hline $\begin{array}{l}\text { Outside the AS } \\
\text { medially }\end{array}$ & $22(20 \%)$ & $36(39 \%)$ & $48(32 \%)$ & $64(49 \%)$ \\
\hline $\begin{array}{l}\text { Outside the AS } \\
\text { laterally }\end{array}$ & $3(3 \%)$ & $2(2 \%)$ & $3(2 \%)$ & $0(0 \%)$ \\
\hline Subtotal & 110 & 93 & 150 & 130 \\
\hline
\end{tabular}

Table 5. The possible symmetry of site of formation of the cephalic vein (CV) in relation to the anatomical snuffbox (AS) between both hands in the same subject

\begin{tabular}{lccc}
\hline $\begin{array}{l}\text { The formation of the CV } \\
\text { in relation to the AS }\end{array}$ & $\begin{array}{c}\text { Total } \\
\text { hands } \\
\text { frequency }\end{array}$ & $\begin{array}{c}\text { Female } \\
\text { hands } \\
\text { frequency }\end{array}$ & $\begin{array}{c}\text { Male } \\
\text { hands } \\
\text { frequency }\end{array}$ \\
\hline Inside the AS distally & $15(3 \%)$ & $8(12.5 \%)$ & $7(16 \%)$ \\
Inside the AS proximally & $51(12 \%)$ & $26(40.5 \%)$ & $25(58 \%)$ \\
Outside the AS medially & $41(10 \%)$ & $30(47 \%)$ & $11(26 \%)$ \\
Outside the AS laterally & $0(0 \%)$ & $0(0 \%)$ & $0(0 \%)$ \\
Total & $\begin{array}{c}\mathbf{1 0 7} \text { out of } \\
\text { (30(25\%) }\end{array}$ & $\mathbf{6 4 0 ( 1 5 \% )}$ & $\mathbf{4 3 0 ( 1 0 \% )}$ \\
\hline
\end{tabular}

larger portion of the hand and forms the $\mathrm{CV}$ which is running on the lateral side of the forearm. Therefore, the AS seems to be located right in the dorsum 
between the hand and the forearm. In addition, we have demonstrated that only in $2 \%$ of the examined hands the CV was neither formed inside the AS nor ran in the AS which has also been demonstrated in a different study where the $\mathrm{CV}$ in some cases was not found in the AS but in the first web space beside the RA and its branches $[1,18]$.

The present study has also investigated any possible patterns for the origin of the $\mathrm{CV}$ in relation to the AS. We have identified two anatomical patterns; one inside the AS named, (pattern A) with $67 \%$ and another pattern outside the AS, named (pattern B) with $37 \%$. Furthermore, pattern $A$ was running either in the proximal or distal parts of the AS. Pattern B was outside the AS either medial or lateral to the AS. These patterns have not been described before to the best of our knowledge and it should be mentioned that they might have been taken as the $\mathrm{CV}$ rather than its origin especially, in the pattern A. Thus, while we indicate that the CV is almost in $98 \%$ of all examined hands was found in AS in the current study, it should be highlighted that both sides (the distal and proximal) of the AS have to be avoided when cannulating or operating the $\mathrm{CV}$, because in these parts of the AS may run the origins of the $\mathrm{CV}$ but not the $\mathrm{CV}$ itself.

An observational study of 200 hands (in 100 living subjects) using tourniquet to study the digital veins, metacarpal veins, dorsal venous arch, cephalic and basilic veins, CV has been observed in three different sites of formation; at first inter digital cleft (in our study it is B1), at AS (in our study it is A1 and A2), and at lateral end of wrist (in our study it is B2). We added a new description of CV location in AS whether it was proximally or distally. The findings of their study confirm ours in that, the most common site of CV formation according to sidedness was in AS, and least common site was outside AS laterally. They found that, in the right hands, $53(53 \%)$ of the hands the CV site of formation was at first inter digital cleft, in 36 (36\%) of the hands was at AS, in 11 $(11 \%)$ of the hands was at lateral end of wrist. While in the left hands, 51 (51\%) of the hands CV site of formation was at first inter digital cleft, in 31 (31\%) of the hands was at AS, in $18(18 \%)$ of the hands was at lateral end of wrist [18]. The observation of the present study was unlike that of a study carried by Matsuo et al. [12]; a study of 32 hands and forearms from 18 cadavers, showed constant existence of the $\mathrm{CV}$, which consistently derived from a collateral vein of the deep palmar arch [11]. The variation of the results between the present study and an aforementioned study could be due to the ethnic variation, as one of the studies confirmed the potential changeable role of ethnicity on the frequency distribution of certain patterns of the superficial veins on the hand [4].

\section{CONCLUSIONS}

The present study has fully examined whether the location of CV in relation to the AS is different in both sexes and both hands. Data obtained in the present study have indicated that the formation of the $\mathrm{CV}$ in the proximal part of the AS was the most common one for the CV in both sexes. However, when the course of CV in the AS was evaluated in both hands in the general population, it was also found that the formation of the CV in the proximal part of the AS is proportionally greater in the right hands. On the contrary, the formation of the CV outside and medial to the AS which was greater in left hands.

The current study has for the first time scrutinized the origin of the CV and its relationship with the AS and demonstrated that the CV was running within the AS in almost $98 \%$ of the examined hands. In addition, the CV has shown two anatomical patterns in its origin; within or outside the AS. These data may help and guide medical personal to better understand the curse of the $\mathrm{CV}$ and its different patterns of origin which may help in better cannulation and setting up arteriovenous fistula.

\section{REFERENCES}

1. Canale ST, Beaty JH. Campbell's operative orthopaedics e-book. Elsevier Health Sciences, Philadelphia 2012.

2. Cerda A, del Sol M. Anatomical snuffbox and it clinical significance: a literature review. Int J Morphol. 2015; 33(4): 1355-1360, doi: 10.4067/s0717-95022015000400027.

3. Tanea C, Younus M, Howale D. The study of dorsal venous arch of hand in living adult males in udaipur district of raasthan. Int J Curr Res Rev. 2012; 4(5): 89-89.

4. Diab M. Lexicon of orthopaedic etymology. 1st ed. Harwood Academic Pub, Newark 1999.

5. Elmegarhi SS, Amarin JZ, Hadidi MT, et al. Dorsal metacarpal veins: anatomic variation and potential clinical implications. Anat Sci Int. 2018; 93(2): 238-243, doi: 10.1007/ s12565-017-0403-0, indexed in Pubmed: 28417223.

6. Grechenig W, Peicha G, Fellinger M, et al. Anatomical and safety considerations in establishing portals used for wrist arthroscopy. Clin Anat. 1999; 12(3): 179-185, doi: 10.1002/(sici)1098-2353(1999)12:3<179::aid-ca6>3.0. co;2-9.

7. Hamzah AA, Ramasamy S, Adnan AS. Pattern of superficial venous of the cubital fossa among volunteers in a tertiary hospital. Trop Med Surg. 2014; 2(2): 104-109, doi: 10.4172/2329-9088.1000164. 
8. Lee SH, Chun KJ, Lee DS, et al. Right cardiac catheterization using the antecubital fossa vein in korean patients. Korean Circ J. 2016; 46(2): 207-212, doi: 10.4070/ kcj.2016.46.2.207, indexed in Pubmed: 27014351.

9. Loukas M, Myers CS, Wartmann ChT, et al. The clinical anatomy of the cephalic vein in the deltopectoral triangle. Folia Morphol. 2008; 67(1): 72-77, indexed in Pubmed: 18335417.

10. Loukas M, Tubbs RS, Feldman J. Netter's introduction to clinical procedures e-book. Elsevier Health Sciences, Philadelphia 2016.

11. Mehigan J, McAlexander R. Snuffbox arteriovenous fistula for hemodialysis. Am J Surg. 1982; 143(2): 252-253, doi: 10.1016/0002-9610(82)90080-0.

12. Matsuo M, Honma S, Sonomura T, et al. Clinical anatomy of the cephalic vein for safe performance of venipuncture. JA Clin Rep. 2017; 3(1): 50, doi: 10.1186/s40981-0170121-6, indexed in Pubmed: 29457094.

13. Naeem R, Soueid A, Lahiri A. The dangers of intravenous cannulation within the anatomical snuffbox. J Hand Surg Eur Vol. 2012; 37(4): 362-363, doi: 10.1177/1753193411433524, indexed in Pubmed: 22190567.

14. Radkowski CA, Richards RS, Pietrobon R, et al. An anatomic study of the cephalic vein in the deltopectoral shoulder approach. Clin Orthop Relat Res. 2006; 442: 139-142, doi: 10.1097/01.blo.0000181146.78434.da, indexed in Pubmed: 16394752.

15. Robson AJ, See MS, Ellis H. Applied anatomy of the superficial branch of the radial nerve. Clin Anat. 2008; 21(1): 38-45, doi: 10.1002/ca.20576, indexed in Pubmed: 18092362.

16. Sadeghi A, Setayesh Mehr M, Esfandiari E, et al. Variation of the cephalic and basilic veins: A case report. J Cardiovasc Thorac Res. 2017; 9(4): 232-234, doi: 10.15171/ jcvtr.2017.40, indexed in Pubmed: 29391938.

17. Salameh MA, Shatarat AT, Badran DH, et al. The best vein to be accessed based on descriptive study of dorsal metacarpal vein. Anat Cell Biol. 2019; 52(4): 390-396, doi: 10.5115/acb.19.142, indexed in Pubmed: 31949977.

18. Samarakoon LB, Lakmal KC, Thillainathan S, et al. Anatomical relations of the superficial sensory branches of the radial nerve: a cadaveric study with clinical implications. Patient Saf Surg. 2011; 5(1): 28, doi: 10.1186/1754-94935-28, indexed in Pubmed: 22054296.

19. Tao W, Dong-Yang G, Meng W, et al. Anatomical snuffbox versus forearm internal arteriovenous fistula for 214 hemodialysis patients with chronic renal failure: Which is the better method for permanent vascular access prior to kidney transplantation. J Clin Rehab Tissue Eng Res. 2010; 14(31): 5837-5840, doi: 10.3969/j.issn.16738225.2010.31.034.

20. Tubbs RS, Salter EG, Oakes WJ. The tabatière anatomique. Clin Anat. 2006; 19(4): 299-303, doi: 10.1002/ca.20151, indexed in Pubmed: 16283634.

21. Tubiana R. The hand. Vol. 1. Sanders, Philadelphia, Penn 1981.

22. Ukoha UU, Oranusi CK, Okafor JI, et al. Patterns of superficial venous arrangement in the cubital fossa of adult Nigerians. Niger J Clin Pract. 2013; 16(1): 104-109, doi: 10.4103/1119-3077.106777, indexed in Pubmed: 23377482 .

23. Thwin SS, Fazlin F, Than M. Multiple variations of the tendons of the anatomical snuffbox. Singapore Med J. 2014; 55(1): 37-40, doi: 10.11622/smedj.2013216, indexed in Pubmed: 24452976.

24. Vialle R, Pietin-Vialle C, Cronier P, et al. Anatomic relations between the cephalic vein and the sensory branches of the radial nerve: How can nerve lesions during vein puncture be prevented? Anesth Analg. 2001; 93(4): 1058-1061, doi: 10.1097/00000539-200110000-00052, indexed in Pubmed: 11574383.

25. Wolowczyk L, Williams AJ, Donovan KL, et al. The snuffbox arteriovenous fistula for vascular access. Eur J Vasc Endovasc Surg. 2000; 19(1): 70-76, doi: 10.1053/ ejvs.1999.0969, indexed in Pubmed: 10706839. 